OPEN ACCESS

Edited by:

Wim Van Hul,

University of Antwerp, Belgium

Reviewed by:

Emma M. Clark

University of Bristol, United Kingdom

Mengning Yan,

Shanghai Jiao Tong University, China

Jan Coenraad Netelenbos,

VU University

Medical Center, Netherlands

*Correspondence:

M. C. Koelé

m.c.koele@amsterdamumc.n!

Specialty section:

This article was submitted to

Bone Research,

a section of the journal

Frontiers in Endocrinology

Received: 02 September 2019 Accepted: 07 January 2020

Published: 24 January 2020

Citation:

Koelé MC, Lems WF and Willems HC (2020) The Clinical Relevance of

Hyperkyphosis: A Narrative Review.

Front. Endocrinol. 11:5.

doi: $10.3389 /$ fendo.2020.00005

\section{The Clinical Relevance of Hyperkyphosis: A Narrative Review}

\author{
M. C. Koelé ${ }^{1 *}$, W. F. Lems ${ }^{2}$ and H. C. Willems ${ }^{1}$ \\ ${ }^{1}$ Division of Geriatrics, Department of Internal Medicine, Academic Medical Centre Amsterdam, Amsterdam Public Health \\ Research Institute, Amsterdam UMC, Amsterdam, Netherlands, ${ }^{2}$ Department of Rheumatology, Amsterdam Movement \\ Sciences, Amsterdam UMC, Vrije Universiteit Amsterdam, Amsterdam, Netherlands
}

The kyphosis angle of the thoracic spine tends to increase with aging. Hyperkyphosis is a kyphosis angle, exceeding the normal range. This narrative literature review aims to provide an overview of the current literature concerning kyphosis measurement methods, the etiology and adverse health effects of hyperkyphosis. As of yet, a well-defined threshold for hyperkyphosis is lacking. To attain more generalizability and to be able to compare study results in older adults, we propose to define age-related hyperkyphosis as a Cobb angle of $50^{\circ}$ or more in standing position. Hyperkyphosis may be a potentially modifiable risk factor for adverse health outcomes, like fall risk and fractures. Additionally, hyperkyphosis may indicate the presence of osteoporosis, which is treatable. Prospective and intervention studies, using a Cobb angle of $50^{\circ}$ as a clear and uniform definition of hyperkyphosis, are warranted to investigate the clinical relevance of hyperkyphosis.

Keywords: hyperkyphosis, kyphosis, older adults, fracture, fall, measurement, review

\section{INTRODUCTION}

Kyphosis is the curvature of the thoracic spine, formed by the shape of the vertebrae and the intervertebral discs and-in standing position-paraspinal muscle strength. Hyperkyphosis is present when the kyphosis angle exceeds the normal ranges. Apart from the consequences of normal aging, like decreasing muscle strength (1) and degenerative changes of the spine (2), other factors contribute to the increase of the kyphosis angle. Vertebral fractures are present in no less than $40 \%$ of the persons with hyperkyphosis (3), and with each vertebral fracture the kyphosis angle increases with $3.8^{\circ}(4)$. There is growing evidence showing an association between hyperkyphosis and negative health effects, like a decreased physical performance and a doubled fall risk (4-15).

Currently, numerous kyphosis measurement methods have been used in literature and a clear definition of hyperkyphosis is lacking. If we had a uniform definition of hyperkyphosis, the association with adverse health effects and prognostic value of hyperkyphosis as well as the effectiveness of interventions could be investigated better. This review aims to provide an updated overview of the current studies and to conclude whether hyperkyphosis is relevant for clinical practice. We will discuss the etiology and adverse health effects of hyperkyphosis, and will focus on kyphosis measurement methods. Based on the literature described, we will propose to define hyperkyphosis as a Cobb angle of $50^{\circ}$ or more in standing position.

\section{METHODS}

We conducted a literature search of PubMed and Embase from 1947 up to now, using the following search terms and derivatives: kyphosis, hyperkyphosis and thoracic spine. We screened the 
abstracts (9238) and included 74 studies assessing kyphosis measurement methods, the pathogenesis of hyperkyphosis or the association with clinically relevant outcomes. We excluded non-English studies, duplicate or overlapping articles intervention studies assessing the effect of surgical procedures and studies in children or in participants with hyperkyphosis caused by disease and scoliosis.

\section{Kyphosis Measurement Methods}

The Cobb angle is considered to be the current gold standard method to measure kyphosis (16). Initially, the Cobb angle was developed to assess scoliosis angles. By modifying the direction of radiographic imaging from frontal to sagittal projection, the Cobb angle became useful to assess kyphosis angles (17). The vertebrae superior to the fourth thoracic vertebra (T4) are often less well visible due to over projection of other structures. Therefore, commonly the angle between T4 and T12 is used. The Cobb angle is measured by drawing a line through the superior endplate of T4 and a second line through the inferior endplate of T12. At the intersection of these two lines, the Cobb angle can be measured (Figure 1).

In addition to the Cobb angle, several clinimetric kyphosis measurement methods have been developed. A protractor is used to measure the kyphosis angle with the Debrunner kyphometer (18), goniometer (19), arcometer (20), and inclinometer (21). The upper arm of the protractor is placed on $\mathrm{C} 7$ or $\mathrm{T} 1$, and the lower arm on T12. Two other devices-the flexicurve ruler (22) and the spinal mouse (23)-document the contour of the spine. The flexicurve ruler is molded to the spine from C7 in caudal direction. The kyphosis index is the width divided by the length of the thoracic curve. The spinal mouse is a device with accelerometers, detecting distance and changes of inclination while rolled over the spine. Finally, the occiput-towall distance (OWD) and the blocks method are used to quantify kyphosis (Figure 2).

Every measurement method has its own characteristics, advantages and disadvantages. While the Cobb angle has the advantage of providing information on the anatomy of the vertebrae and spinal alignment, radiation exposure is inevitable. High interrater and intrarater reliability have been described in studies with well-trained examiners to score the Cobb angles. The correlation coefficients range from 0.80 to 1.00 $(4,7,24,25)$, which may be expected to be lower when performed in clinical practice by less experienced examiners. The clinimetric measurement methods make radiation exposure redundant. Some clinimetric measurement methods are easy to use in clinical practice and the result instantly available.

However, the correlation with the Cobb angle ranges extensively from low (0.28) to high (up to 0.92$)(7,19,24,26-28)$. These large differences may be explained by the variety in kyphosis measurement methods regarding the position of the person during measurement and which part of the spine is measured. In supine position, the back is passively stretched and the influence of muscle strength may be diminished when compared to a standing position. Most of the measurement methods only measure the curve of the thoracic spine. Yet the

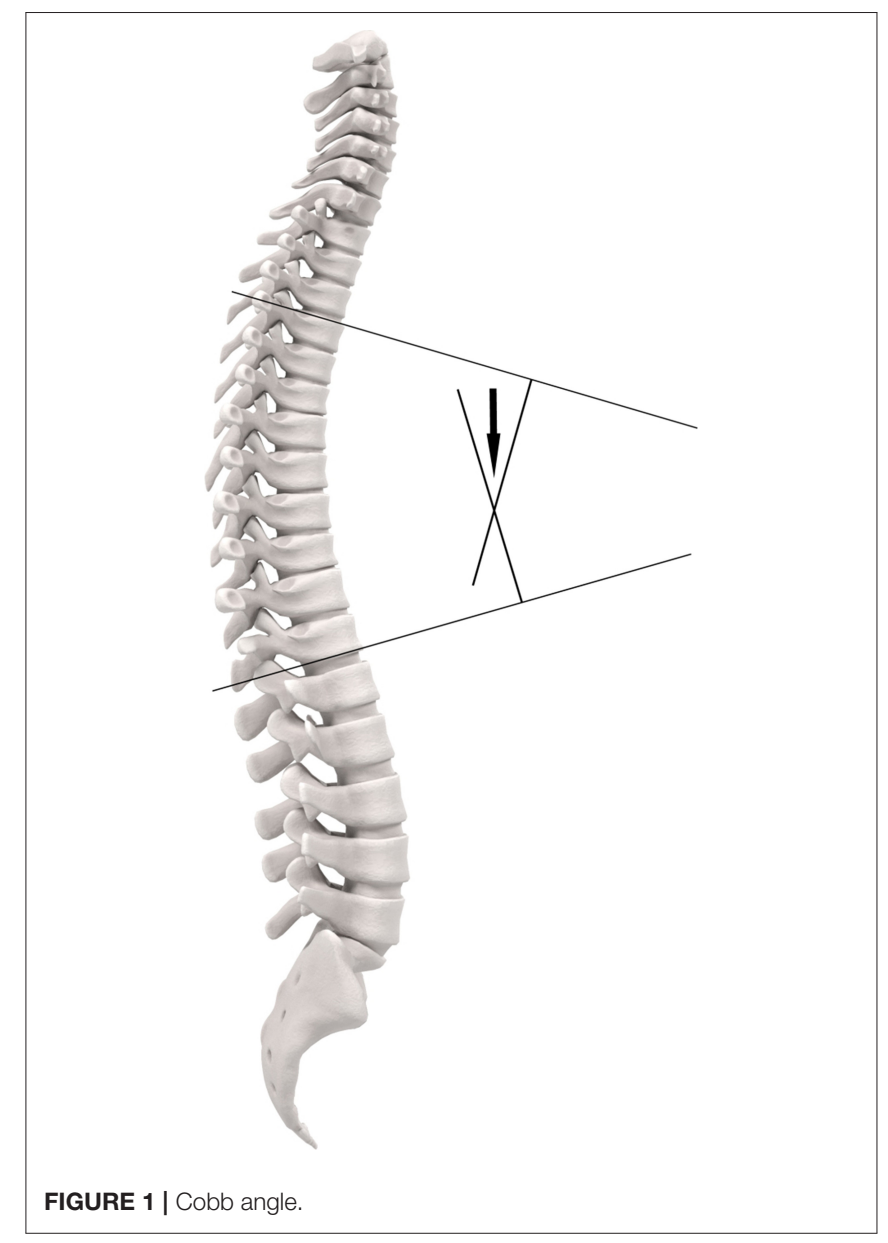

blocks method also takes the cervical spine into account, and the OWD is influenced by the posture of the patient when standing.

Thus, in addition to the gold standard kyphosis measurement-the Cobb angle-various kyphosis measurement methods have been used in literature. Correlation among the measurement methods ranges extensively, possibly reflecting the large differences between methods.

\section{Definition}

With aging, kyphosis tends to increase. In younger adults, the Cobb angle averages from 20 to $29^{\circ}$ (17). After the fourth decade, the kyphosis angle increases (17). In two cohort studies among older women, the Cobb angle increased with $2.6^{\circ}$ in 3 years and $7^{\circ}$ in 15 years (5), and 3.9 in 4 years (29). The mean kyphosis angle ranges from 35 to $38^{\circ}$ in adults, aged 65 years and older $(30,31)$. In a cohort of older End Stage Renal Disease patients, the mean Cobb angle was $41^{\circ}$ (32). In another cohort with women aged 65 years and older, the mean kyphosis angle increased with age from 47 to $52^{\circ}$ (33). However, these values were measured in a cohort with underlying osteoporosis, with potentially more vertebral fractures and thereby a higher mean Cobb angle than the general population.

Currently, a well-defined threshold, differentiating between normal kyphosis and hyperkyphosis, is lacking. In some studies, the 95th percentile of the Cobb angle in younger adults is 


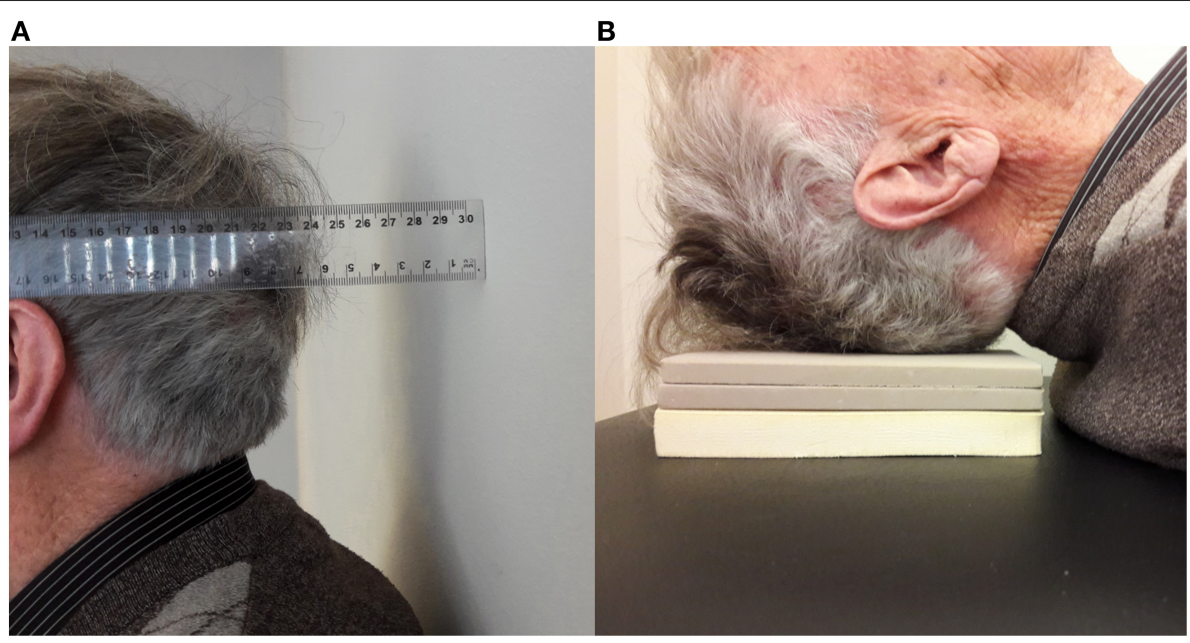

FIGURE 2 | (A) Occiput-to-wall distance and (B) Blocks method.

used as threshold (17). As the mean angle in older adults ranges from 35 to $52^{\circ}$, the prevalence of hyperkyphosis may be overestimated in these studies. In other studies, a higher threshold value of $50^{\circ}$ is used $(6,14,29,34)$. When using these threshold values, hyperkyphosis is present in $20-40 \%$ of the older adults $(7,27,35,36)$. Even higher prevalences of up to $55 \%$ are reported in a geriatric population (14). The abundance of kyphosis measurement methods makes a large number of other definitions of hyperkyphosis necessary. Yet for some measurement methods no threshold value could be found in literature, and for some kyphosis measurement methods the threshold value differs between studies. McDaniels-Davidson et al. defined hyperkyphosis as $54^{\circ}$, measured with the Debrunner kyphometer and 17, measured with the Flexicurve ruler (6). Hyperkyphosis, measured with the OWD, is defined in literature as $4 \mathrm{~cm}(15,37)$ or $5 \mathrm{~cm}(14,38)$. Different threshold values to define hyperkyphosis are used for the blocks method: $\geq 1$ block (39), $\geq 2$ blocks $(36,40)$, and $\geq 4$ blocks (6).

In conclusion, a large number of kyphosis measurement methods with various threshold values for hyperkyphosis are used in addition to the gold standard method, the Cobb angle Generalizability and comparison of study results is therefore limited. Though preferable in order to pursue more uniformity in hyperkyphosis research, differentiating between normal and abnormal kyphosis angles remains difficult.

\section{PATHOGENESIS}

\section{Vertebral Fractures and Degenerative Disc Disease}

The pathogenesis of hyperkyphosis has not yet been completely elucidated. Anterior wedging of the vertebrae and asymmetrical compression of the intervertebral discs may result in an increase of the kyphosis angle (41). In adults with vertebral fractures, hyperkyphosis is more prevalent $(3,33,42)$. Kado et al. showed that with each compression fracture, the kyphosis angle increased with $3.8^{\circ}$ (4). Yet, only $40 \%$ of the patients with hyperkyphosis has vertebral fractures (3), which suggests that other risk factors may play a role. With aging, the intervertebral discs desiccate. This process is referred to as degenerative disc disease. Manns et al. showed a significant correlation between anterior disc height and kyphosis angle $(r=-0.34, p<0.001)$ and a negative correlation to age $(r=-0.30, p=0.01)$, potentially indicating that disc degeneration is not a disease, but merely part of normal aging (43).

As most studies are cross-sectional, it is unclear whether degenerative disc disease is a cause or consequence of hyperkyphosis. Only Kado et al. has reported an association between degenerative disc disease and hyperkyphosis-and not kyphosis progression-in a longitudinal study. However, due to the retrospective design, no conclusions could be drawn on causality of the two phenomena (4). Another possibility is that-rather than being cause or consequence-degenerative disc disease and hyperkyphosis enhance each other. Anterior compression of the intervertebral discs may increase the kyphosis angle, and this in turn may enhance further compression of the discs.

\section{Muscle Strength}

Besides the vertebrae and intervertebral discs, paraspinal muscle strength may influence kyphosis. Back extensor muscle strength has been shown to be inversely correlated to kyphosis $(44,45)$. Hyperkyphosis may be an indicator of frailty, as grip strength is one of the Fried criteria. However, the association between kyphosis angle and grip strength remains controversial, as some cohort studies report a positive association $(9,40)$, and others a negative association $(5,46)$.

\section{Genetic Predisposition}

In some heritable diseases like Scheuermann's disease, hyperkyphosis is seen at an early age. Kado et al. reported that independent of vertebral fractures and bone mineral density 
(BMD), women with 1-2 parents with hyperkyphosis had on average $2.6^{\circ}$ worse kyphosis angle compared to women with parents without hyperkyphosis (4). A twin study among 241 twins found a heritability estimate of $61 \%$ (95\%CI 46-72) (47). In the Framingham study, the heritability estimate was reported to be $54 \%$ (95\%CI 43-64\%) (48). Mouse knock-out and transgenic models show that hyperkyphosis may be enhanced by mutations in the genes involved in DNA repair and delaying senescence $(49,50)$.

\section{ADVERSE HEALTH EFFECTS OF HYPERKYPHOSIS}

\section{Physical Performance}

A large number of cohort studies has investigated the association of the kyphosis angle and physical performance $(4,5,7-11,51)$. In all studies, except the study of Demarteau et al., multivariate analyses were performed to adjust for age and comorbidity including vertebral fractures or BMD. Only Katzman et al. investigated this association prospectively in a large cohort of women (mean age 68 years) (5). Performance time on the Timed Up and Go test (TUG) increased with increasing kyphosis angle. Although statistically significant, the effect size of this difference is very small. Similar to this study, all studies consistently report a statistical significant lower physical performance in hyperkyphotic participants, potentially indicating publication bias. Yet, various kyphosis measurement methods and physical performance tests have been used, and reported differences are small. Therefore, the clinical relevance of this association between hyperkyphosis and physical performance is questionable.

\section{Falls}

The majority of studies, including two studies with a prospective design, show that hyperkyphosis is associated with falls $(6,12,14,15,39)$. One relatively small study $(n=73)$ may have overestimated the association, as age was not added in the multivariate analyses (12). One prospective and two crosssectional studies found no association between hyperkyphosis and falls $(13,32,52)$.

The underlying cause of the increased fall risk in older adults with an increased kyphosis angle may be balance disruption due to a forward shift of the center of gravity of the body (53). Indeed, older adults with hyperkyphosis have an increased postural sway, wider stance and reduced gait speed $(38,53)$. However, conflicting results have been reported on the association between balance and hyperkyphosis. Some studies report a positive correlation $(13,34,54)$, while others found no correlation between hyperkyphosis and impaired balance $(7,55)$. This difference may partly be explained by the balance test used, as clinical tests like used in one of the two negative studies (7), may be less sensitive to detect balance problems than post-urography, which is used in the studies reporting a positive association. Significant methodological limitations of the before mentioned studies may be a second reason for the conflicting results of the studies $(7,34,54,55)$. Only the study of Ishikawa et al. adjusted for potential confounders (13).
In conclusion, the majority of studies shows that in adjusted analyses, hyperkyphosis is associated to falls. Whether impaired balance is the underlying mechanism of the increased fall risk in persons with hyperkyphosis, is currently unknown.

\section{Fractures}

Hyperkyphosis increases pressure on the anterior part of the vertebrae. Consequent vertebral fractures may therefore be expected. Huang et al. indeed reported an increased risk of vertebral fractures in women (mean age 71 years) with hyperkyphosis (adjusted OR 1.7, 95\%CI 1.0-3.0) (25). This is confirmed in another longitudinal study of Kado et al. in women (mean age 69 years) with hyperkyphosis (HR 1.50, 95\%CI 1.102.06, model adjusted for age and BMD). Change of the Cobb angle was also independently associated to fracture risk (HR $1.28,95 \%$ CI 1.06-1.55) (29). Opposite to these results, one large cohort study among older women (mean age 68 years) with low BMD or prevalent vertebral fracture reported no association (IRR 1.08, 95\%CI 0.96-1.22, model adjusted for age and BMD). Change of the kyphosis angle was not associated with fracture risk (42).

Thus, conflicting results regarding the association between hyperkyphosis and future fractures have been reported in women with low $\operatorname{BMD}(25,29,42)$. These differences may be explained by the difference in regression models applied in the studies. The studies reporting a positive association have applied logistic regression and Cox regression, while the study reporting no association used Poisson regression. The chance of a future vertebral fracture is dependent on previous fractures. Therefore, the standard error is smaller and the confidence interval too narrow, which makes the test statistic too high and the estimated effect of the predictor on the outcome too high. Poisson regression corrects for the type I error caused by the correlation between a first fracture and next fractures. Therefore, the studies of Huang et al. and Kado et al. may have overestimated the effect of hyperkyphosis on fracture incidence.

\section{Pulmonary Function}

Literature on the association of hyperkyphosis with pulmonary function is scarce. Increased thoracic kyphosis may cause mechanical restriction of pulmonary function, as reported in all four articles included in the systematic review of Harrison et al. (56). Older adults with hyperkyphosis have more often dyspnoea and decreased vital capacity $(57,58)$ and forced expiratory volume $(58,59)$. Lombardi et al. was the only study, in which correlations were unadjusted (58). The retrospective study of Lee et al., found no association with acute respiratory failure in 51 hyperkophotic participants (unadjusted HR 3.20, 95\%CI 0.86-12.14) (60).

Thus, consistent results on the association between hyperkyphosis and pulmonary function have been reported, though internal and external validity of the studies is limited. Whether hyperkyphosis leads to a higher incidence of diseases like pneumonia or COPD, is yet unknown. 


\section{Mortality}

Four large cohort studies report that hyperkyphosis is associated with a higher all-cause mortality $(32,36,61,62)$. In the RanchoBernardo cohort, the odds ratio was 1.40 (95\%CI 1.07-1.82) in the multivariable model adjusted for age, gender, smoking, physical activity and BMD (36). Goto et al. reported an association between hyperkyphosis and mortality in end stage renal disease patients, yet they may have overestimated the association as they did not adjust for potential confounders (32). Mortality rates increase with increasing kyphosis angle in older women with osteoporosis in the for age and comorbidity adjusted model (61), possibly reflecting the number of osteoporotic fractures and thus the severity of osteoporosis.

\section{Pain}

Remarkably, only in a few studies the association between hyperkyphosis and pain has been investigated (33, 63-65). Three out of four studies adjusted for age $(33,63,64)$. All studies except Ettinger et al. (63) report a positive correlation or association with pain.

\section{Quality of Life}

As mentioned above, several negative health conditions, like pain and lower physical performance, have been linked to hyperkyphosis. Lower quality of life may therefore be a logical consequence. Less satisfaction with life in participants with a larger kyphosis angle has been described (66-68). However, results are difficult to interpret due to significant methodological limitations. Only Martin et al. adjusted for potential confounders, i.e., age and BMD (66).

\section{DISCUSSION AND CONCLUSION}

Hyperkyphosis is common in older adults. This review reveals several shortcomings in the literature concerning the clinical relevance of hyperkyphosis.

First of all, a well-defined threshold for hyperkyphosis is lacking. Yet, in order to attain more uniformity in research, applying one clear definition of hyperkyphosis is essential. As the Cobb angle is the gold standard kyphosis measurement method, a definition of hyperkyphosis based on the Cobb is preferable. The mean kyphosis angle has been reported to range from 35 to $42^{\circ}$ in adults aged 65 years and older $(30-32,69)$,

\section{REFERENCES}

1. Baumgartner RN, Waters DL, Gallagher D, Morley JE, Garry PJ. Predictors of skeletal muscle mass in elderly men and women. Mech. Ageing Dev. (1999) 107:123-36. doi: 10.1016/S0047-6374(98)00130-4

2. Hinman MR. Comparison of thoracic kyphosis and postural stiffness in younger and older women. Spine J. (2004) 4:4137. doi: 10.1016/j.spinee.2004.01.002

3. Schneider DL, von Muhlen D, Barrett-Connor E, Sartoris DJ. Kyphosis does not equal vertebral fractures: the Rancho Bernardo study. J Rheumatol. (2004) 31:747-52.

4. Kado DM, Huang MH, Karlamangla AS, Cawthon P, Katzman W, Hillier TA, et al. Factors associated with kyphosis progression in older women: 15 years' with a larger mean angle of $47-52^{\circ}$ in older women with osteoporosis. We need to take the measurement error into account, as the interrater and intrarater variability ranges from 3 to $5^{\circ}(70,71)$. Defining hyperkyphosis based on means and interrater and intrarater variability may be preferable, as a definition based on the association with adverse health outcomes would only be applicable in similar populations. Based on the range of the mean kyphosis angle in older adults and interrater and intrarater variability, we propose to define hyperkyphosis as a Cobb angle of $50^{\circ}$ or more in standing position. Additionally, identifying a pre-stage of hyperkyphosis-a Cobb angle ranging from 40 to $50^{\circ}$-may facilitate early recognition and potential intervention.

Secondly, many cohort studies report an association between hyperkyphosis and adverse health effects. However, most studies have a cross-sectional design and some outcome measures have been scantly investigated. Moreover, most studies have been performed in a population with osteoporosis. In order to gain knowledge on the consequences of hyperkyphosis, more prospective studies are warranted in other populations. While literature concerning the consequences of hyperkyphosis may be limited, osteoporotic vertebral fractures have consistently been identified as one of the causes of hyperkyphosis. Therefore, hyperkyphosis may be a clear clinical sign of the presence of osteoporosis. As osteoporosis is treatable, early recognition is highly important to prevent future fractures and the accompanying health-related problems. Finally, a few small intervention studies have shown that hyperkyphosis in itself is treatable through targeted training of back extensor muscles or yoga (72-75).

In conclusion, hyperkyphosis is a clinical sign of the presence of osteoporosis, and a potentially modifiable risk factor for adverse health outcomes. Prospective and intervention studies, using a Cobb angle of $50^{\circ}$ as a clear and uniform definition of hyperkyphosis, are warranted to investigate the clinical relevance of hyperkyphosis.

\section{AUTHOR CONTRIBUTIONS}

MK performed the literature search and wrote the draft. MK and HW read the articles. WL and HW reviewed the draft of the article and provided expertise for revisions. All authors approved the submitted version of the manuscript. 28:179-87. doi: 10.1002/jbmr.1728

5. Katzman WB, Vittinghoff E, Ensrud K, Black DM, Kado DM. Increasing kyphosis predicts worsening mobility in older communitydwelling women: a prospective cohort study. J Am Geriatr Soc. (2011) 59:96-100. doi: 10.1111/j.1532-5415.2010.03214.x

6. McDaniels-Davidson C, Davis A, Wing D, Macera C, Lindsay SP, Schousboe JT, et al. Kyphosis and incident falls among community-dwelling older adults. Osteoporos Int. (2017) 29:163-9. doi: 10.1007/s00198-017-4253-3

7. Katzman WB, Harrison SL, Fink HA, Marshall LM, Orwoll E, BarrettConnor E, et al. Physical function in older men with hyperkyphosis. $J$ Gerontol Series A Biol Sci Med Sci. (2015) 70:635-40. doi: 10.1093/gerona/ glu213 
8. Eum R, Leveille SG, Kiely DK, Kiel DP, Samelson EJ, Bean JF. Is kyphosis related to mobility, balance, and disability? Am J Phys Med Rehabil. (2013) 92:980-9. doi: 10.1097/PHM.0b013e31829233ee

9. Katzman WB, Huang MH, Lane NE, Ensrud KE, Kado DM. Kyphosis and decline in physical function over 15 years in older community-dwelling women: the Study of Osteoporotic Fractures. J Gerontol Series A Biol Sci Med Sci. (2013) 68:976-83. doi: 10.1093/gerona/glt009

10. Katzman WB, Vittinghoff E, Kado DM. Age-related hyperkyphosis, independent of spinal osteoporosis, is associated with impaired mobility in older community-dwelling women. Osteoporos Int. (2011) 22:8590. doi: 10.1007/s00198-010-1265-7

11. Antonelli-Incalzi R, Pedone C, Cesari M, Di Iorio A, Bandinelli S, Ferrucci L. Relationship between the occiput-wall distance and physical performance in the elderly: a cross sectional study. Aging Clin Exp Res. (2007) 19:20712. doi: $10.1007 / \mathrm{BF} 03324691$

12. Arnold CM, Busch AJ, Schachter CL, Harrison L, Olszynski W. The relationship of intrinsic fall risk factors to a recent history of falling in older women with osteoporosis. J Orthopaed Sports Phys Therap. (2005) 35:452-60. doi: 10.2519/jospt.2005.35.7.452

13. Ishikawa Y, Miyakoshi N, Kasukawa Y, Hongo M, Shimada Y. Spinal sagittal contour affecting falls: cut-off value of the lumbar spine for falls. Gait Posture. (2013) 38:260-3. doi: 10.1016/j.gaitpost.2012.11.024

14. van der Jagt-Willems HC, de Groot MH, van Campen JP, Lamoth CJ, Lems WF. Associations between vertebral fractures, increased thoracic kyphosis, a flexed posture and falls in older adults: a prospective cohort study. $B M C$ Geriatr. (2015) 15:34. doi: 10.1186/s12877-015-0018-z

15. Tominaga R, Fukuma S, Yamazaki S, Sekiguchi M, Otani K, Kikuchi S, et al. Relationship between kyphotic posture and falls in community-dwelling men and women: the locomotive syndrome and health outcome in aizu cohort study. Spine. (2016) 41:1232-8. doi: 10.1097/BRS.0000000000001602

16. Roghani T, Zavieh MK, Manshadi FD, King N, Katzman W. Age-related hyperkyphosis: update of its potential causes and clinical impacts-narrative review. Aging Clin Exp Res. (2016) 29:567-77. doi: 10.1007/s40520-0160617-3

17. Fon GT, Pitt MJ, Thies AC, Jr. Thoracic kyphosis: range in normal subjects. Am J Roentgenol. (1980) 134:979-83. doi: 10.2214/ajr.134.5.979

18. Debrunner HU. [The Kyphometer]. Zeitschrift fur Orthopadie und ihre Grenzgebiete. (1972) 110:389-92.

19. Perriman DM, Scarvell JM, Hughes AR, Ashman B, Lueck CJ, Smith PN. Validation of the flexible electrogoniometer for measuring thoracic kyphosis. Spine. (2010) 35:E633-40. doi: 10.1097/BRS.0b013e3181d13039

20. Chaise FO, Candotti CT, Torre ML, Furlanetto TS, Pelinson PP, Loss JF. Validation, repeatability and reproducibility of a noninvasive instrument for measuring thoracic and lumbar curvature of the spine in the sagittal plane. Revista Brasileira de Fisioterapia. (2011) 15:511-7. doi: 10.1590/S1413-35552011005000031

21. Aaro S, Ohlen G. The effect of Harrington instrumentation on the sagittal configuration and mobility of the spine in scoliosis. Spine. (1983) 8:5705. doi: 10.1097/00007632-198309000-00002

22. Milne JS, Lauder IJ. Age effects in kyphosis and lordosis in adults. Ann Hum Biol. (1974) 1:327-37. doi: 10.1080/03014467400000351

23. Mannion AF, Knecht K, Balaban G, Dvorak J, Grob D. A new skinsurface device for measuring the curvature and global and segmental ranges of motion of the spine: reliability of measurements and comparison with data reviewed from the literature. Eur Spine J. (2004) 13:12236. doi: 10.1007/s00586-003-0618-8

24. Lundon KM, Li AM, Bibershtein S. Interrater and intrarater reliability in the measurement of kyphosis in postmenopausal women with osteoporosis. Spine. (1998) 23:1978-85. doi: 10.1097/00007632-199809150-00013

25. Huang MH, Barrett-Connor E, Greendale GA, Kado DM. Hyperkyphotic posture and risk of future osteoporotic fractures: the Rancho Bernardo study. J Bone Miner Res. (2006) 21:419-23. doi: 10.1359/JBMR.051201

26. Kado DM, Christianson L, Palermo L, Smith-Bindman R, Cummings SR, Greendale GA. Comparing a supine radiologic versus standing clinical measurement of kyphosis in older women: the Fracture Intervention Trial. Spine. (2006) 31:463-7. doi: 10.1097/01.brs.0000200131.01313.a9

27. Tran TH, Wing D, Davis A, Bergstrom J, Schousboe JT, Nichols JF, et al. Correlations among four measures of thoracic kyphosis in older adults. Osteoporos Int. (2016) 27:1255-9. doi: 10.1007/s00198-015-3368-7
28. Greendale GA, Nili NS, Huang MH, Seeger L, Karlamangla AS. The reliability and validity of three non-radiological measures of thoracic kyphosis and their relations to the standing radiological Cobb angle. Osteoporos Int. (2011) 22:1897-905. doi: 10.1007/s00198-010-1422-z

29. Kado DM, Miller-Martinez D, Lui LY, Cawthon P, Katzman WB, Hillier TA, et al. Hyperkyphosis, kyphosis progression, and risk of non-spine fractures in older community dwelling women: the study of osteoporotic fractures (SOF). J Bone Miner Res. (2014) 29:2210-6. doi: 10.1002/jbmr.2251

30. Lorbergs AL, Murabito JM, Jarraya M, Guermazi A, Allaire BT, Yang L, et al. Thoracic Kyphosis and Physical Function: The Framingham Study. J Am Geriatr Soc. (2017) 65:2257-64. doi: 10.1111/jgs.15038

31. Katzman WB, Miller-Martinez D, Marshall LM, Lane NE, Kado DM. Kyphosis and paraspinal muscle composition in older men: a cross-sectional study for the Osteoporotic Fractures in Men (MrOS) research group. BMC Musculoskeletal Disord. (2014) 15:19. doi: 10.1186/1471-2474-15-19

32. Goto NA, Koele MC, van Loon IN, Boereboom FTJ, Verhaar MC, Emmelot-Vonk MH, et al. Thoracic vertebral fractures and hyperkyphosis in elderly patients with end-stage kidney disease; do these patients have different clinical outcomes? Bone. (2019) 127:181-7. doi: 10.1016/j.bone. 2019.06.007

33. Ensrud KE, Black DM, Harris F, Ettinger B, Cummings SR. Correlates of kyphosis in older women. The fracture intervention trial research group. J Am Geriatr Soc. (1997) 45:682-7. doi: 10.1111/j.1532-5415.1997.tb01470.x

34. Sinaki M, Brey RH, Hughes CA, Larson DR, Kaufman KR. Balance disorder and increased risk of falls in osteoporosis and kyphosis: significance of kyphotic posture and muscle strength. Osteoporos Int. (2005) 16:100410. doi: 10.1007/s00198-004-1791-2

35. Ryan SD, Fried LP. The impact of kyphosis on daily functioning. J Am Geriatr Soc. (1997) 45:1479-86. doi: 10.1111/j.1532-5415.1997.tb03199.x

36. Kado DM, Huang MH, Karlamangla AS, Barrett-Connor E, Greendale GA. Hyperkyphotic posture predicts mortality in older community-dwelling men and women: a prospective study. J Am Geriatr Soc. (2004) 52:16627. doi: $10.1111 / \mathrm{j} .1532-5415.2004 .52458 . \mathrm{x}$

37. Siminoski K, Warshawski RS, Jen H, Lee KC. The accuracy of clinical kyphosis examination for detection of thoracic vertebral fractures: comparison of direct and indirect kyphosis measures. J Musculoskeletal Neuronal Int. (2011) 11:249-56.

38. Balzini L, Vannucchi L, Benvenuti F, Benucci M, Monni M, Cappozzo A, et al. Clinical characteristics of flexed posture in elderly women. J Am Geriatr Soc. (2003) 51:1419-26. doi: 10.1046/j.1532-5415.2003.51460.x

39. Kado DM, Huang MH, Nguyen CB, Barrett-Connor E, Greendale GA. Hyperkyphotic posture and risk of injurious falls in older persons: the Rancho Bernardo Study. J Gerontol Series A Biol Sci Med Sci. (2007) 62:6527. doi: $10.1093 /$ gerona/62.6.652

40. Kado DM, Huang MH, Barrett-Connor E, Greendale GA. Hyperkyphotic posture and poor physical functional ability in older community-dwelling men and women: the Rancho Bernardo study. J Gerontol Series A Biol Scie Med Sci. (2005) 60:633-7. doi: 10.1093/gerona/60.5.633

41. Goh S, Price RI, Leedman PJ, Singer KP. The relative influence of vertebral body and intervertebral disc shape on thoracic kyphosis. Clin Biomech. (1999) 14:439-48. doi: 10.1016/S0268-0033(98)00105-3

42. Katzman WB, Vittinghoff E, Kado DM, Lane NE, Ensrud KE, Shipp K. Thoracic kyphosis and rate of incident vertebral fractures: the Fracture Intervention Trial. Osteoporos Int. (2016) 27:899-903. doi: 10.1007/s00198-015-3478-2

43. Manns RA, Haddaway MJ, McCall IW, Cassar Pullicino V, Davie MW. The relative contribution of disc and vertebral morphometry to the angle of kyphosis in asymptomatic subjects. Clin Radiol. (1996) 51:25862. doi: 10.1016/S0009-9260(96)80342-4

44. Sinaki M, Itoi E, Rogers JW, Bergstralh EJ, Wahner HW. Correlation of back extensor strength with thoracic kyphosis and lumbar lordosis in estrogen-deficient women. Am J Phys Med Rehabil. (1996) 75:370-4. doi: 10.1097/00002060-199609 000-00013

45. Mika A, Unnithan VB, Mika P. Differences in thoracic kyphosis and in back muscle strength in women with bone loss due to osteoporosis. Spine. (2005) 30:241-6. doi: 10.1097/01.brs.0000150521.10071.df

46. Abe Y, Aoyagi K, Tsurumoto T, Chen CY, Kanagae M, Mizukami S, et al. Association of spinal inclination with physical performance measures among 
community-dwelling Japanese women aged 40 years and older. Geriatr Gerontol Int. (2013) 13:881-6. doi: 10.1111/ggi.12020

47. Stone MA, Osei-Bordom DC, Inman RD, Sammon C, Wolber LE, Williams FM. Heritability of spinal curvature and its relationship to disc degeneration and bone mineral density in female adult twins. Eur Spine J. (2015) 24:238794. doi: 10.1007/s00586-014-3477-6

48. Yau MS, Demissie S, Zhou Y, Anderson DE, Lorbergs AL, Kiel DP, et al. Heritability of thoracic spine curvature and genetic correlations with other spine traits: the framingham study. J Bone Miner Res. (2016) 31:207784. doi: 10.1002/jbmr.2925

49. de Boer J, Andressoo JO, de Wit J, Huijmans J, Beems RB, van Steeg H, et al. Premature aging in mice deficient in DNA repair and transcription. Science. (2002) 296:1276-9. doi: 10.1126/science.1070174

50. Tyner SD, Venkatachalam S, Choi J, Jones S, Ghebranious N, Igelmann $\mathrm{H}$, et al. p53 mutant mice that display early ageing-associated phenotypes. Nature. (2002) 415:45-53. doi: 10.1038/415045a

51. Demarteau J, Jansen B, Van Keymolen B, Mets T, Bautmans I. Trunk inclination and hip extension mobility, but not thoracic kyphosis angle, are related to 3D-accelerometry based gait alterations and increased fall-risk in older persons. Gait Posture. (2019) 72:89-95. doi: 10.1016/j.gaitpost.2019.05.027

52. O'Brien K, Culham E, Pickles B. Balance and skeletal alignment in a group of elderly female fallers and nonfallers. J Gerontol Series A Biol Sci Med Sci. (1997) 52:B221-6. doi: 10.1093/gerona/52A.4.B221

53. de Groot MH, van der Jagt-Willems HC, van Campen JP, Lems WF, Beijnen $\mathrm{JH}$, Lamoth CJ. A flexed posture in elderly patients is associated with impairments in postural control during walking. Gait Posture. (2014) 39:76772. doi: 10.1016/j.gaitpost.2013.10.015

54. Lynn SG, Sinaki M, Westerlind KC. Balance characteristics of persons with osteoporosis. Arch Phys Med Rehabil. (1997) 78:273-7. doi: 10.1016/S0003-9993(97)90033-2

55. Greig AM, Bennell KL, Briggs AM, Wark JD, Hodges PW. Balance impairment is related to vertebral fracture rather than thoracic kyphosis in individuals with osteoporosis. Osteoporos Int. (2007) 18:543-51. doi: 10.1007/s00198-006-0277-9

56. Harrison RA, Siminoski K, Vethanayagam D, Majumdar SR. Osteoporosisrelated kyphosis and impairments in pulmonary function: a systematic review. J Bone Miner Res. (2007) 22:447-57. doi: 10.1359/jbmr.061202

57. Di Bari M, Chiarlone M, Matteuzzi D, Zacchei S, Pozzi C, Bellia V, et al. Thoracic kyphosis and ventilatory dysfunction in unselected older persons: an epidemiological study in Dicomano, Italy. J Am Geriatr Soc. (2004) 52:90915. doi: 10.1111/j.1532-5415.2004.52257.x

58. Lombardi I, Jr., Oliveira LM, Mayer AF, Jardim JR, Natour J. Evaluation of pulmonary function and quality of life in women with osteoporosis. Osteoporos Int. (2005) 16:1247-53. doi: 10.1007/s00198-005-1834-3

59. Lorbergs AL, O’Connor GT, Zhou Y, Travison TG, Kiel DP, Cupples LA, et al. Severity of kyphosis and decline in lung function: the Framingham Study. J Gerontol Series A Biol Sci Med Sci. (2017) 72:689-94. doi: 10.1093/gerona/glw124

60. Lee SJ, Chang JY, Ryu YJ, Lee JH, Chang JH, Shim SS, et al. Clinical features and outcomes of respiratory complications in patients with thoracic hyperkyphosis. Lung. (2015) 193:1009-15. doi: 10.1007/s00408-015-9795-6

61. Kado DM, Browner WS, Palermo L, Nevitt MC, Genant HK, Cummings SR. Vertebral fractures and mortality in older women: a prospective study. Study of Osteoporotic Fractures Research Group. Arch Int Med. (1999) 159:121520. doi: 10.1001/archinte.159.11.1215

62. Kado DM, Lui LY, Ensrud KE, Fink HA, Karlamangla AS, Cummings SR. Hyperkyphosis predicts mortality independent of vertebral osteoporosis in older women. Ann Int Med. (2009) 150:681-7. doi: 10.7326/0003-4819-150-10-200905190-00005
63. Ettinger B, Black DM, Palermo L, Nevitt MC, Melnikoff S, Cummings SR. Kyphosis in older women and its relation to back pain, disability and osteopenia: the study of osteoporotic fractures. Osteoporos Int. (1994) 4:5560. doi: 10.1007/BF02352262

64. Spencer L, McKenna L, Fary R, Jacques A, Briffa K. Upper back pain in postmenopausal women and associated physical characteristics. PLOS ONE. (2019) 14:e0220452. doi: 10.1371/journal.pone.0220452

65. Ryan PJ, Blake G, Herd R, Fogelman I. A clinical profile of back pain and disability in patients with spinal osteoporosis. Bone. (1994) 15:2730. doi: 10.1016/8756-3282(94)90887-7

66. Martin AR, Sornay-Rendu E, Chandler JM, Duboeuf F, Girman CJ, Delmas PD. The impact of osteoporosis on quality-of-life: the OFELY cohort. Bone. (2002) 31:32-6. doi: 10.1016/S8756-3282(02)00787-1

67. Sangtarash F, Manshadi FD, Sadeghi A. The relationship of thoracic kyphosis to gait performance and quality of life in women with osteoporosis. Osteoporos Int. (2015) 26:2203-8. doi: 10.1007/s00198-015-3143-9

68. Takahashi T, Ishida K, Hirose D, Nagano Y, Okumiya K, Nishinaga M, et al. Trunk deformity is associated with a reduction in outdoor activities of daily living and life satisfaction in community-dwelling older people. Osteoporos Int. (2005) 16:273-9. doi: 10.1007/s00198-004-1669-3

69. Bartynski WS, Heller MT, Grahovac SZ, Rothfus WE, Kurs-Lasky M. Severe thoracic kyphosis in the older patient in the absence of vertebral fracture: association of extreme curve with age. Am J Neuroradiol. (2005) 26:2077-85.

70. Carman DL, Browne RH, Birch JG. Measurement of scoliosis and kyphosis radiographs. Intraobserver and interobserver variation. J Bone Joint Surg Am Vol. (1990) 72:328-33. doi: 10.2106/00004623-19907203 0-00003

71. Stotts AK, Smith JT, Santora SD, Roach JW, D'Astous JL. Measurement of spinal kyphosis: implications for the management of Scheuermann's kyphosis. Spine. (2002) 27:2143-6. doi: 10.1097/00007632-200210010-00013

72. Katzman WB, Parimi N, Gladin A, Poltavskiy EA, Schafer AL, Long RK, et al. Sex differences in response to targeted kyphosis specific exercise and posture training in community-dwelling older adults: a randomized controlled trial. BMC Musculoskel Disord. (2017) 18:509. doi: 10.1186/s12891-017-1862-0

73. Katzman WB, Vittinghoff E, Lin F, Schafer A, Long RK, Wong S, et al. Targeted spine strengthening exercise and posture training program to reduce hyperkyphosis in older adults: results from the study of hyperkyphosis, exercise, and function (SHEAF) randomized controlled trial. Osteoporos Int. (2017) 28:2831-41. doi: 10.1007/s00198-017-4109-x

74. Greendale GA, Huang MH, Karlamangla AS, Seeger L, Crawford S. Yoga decreases kyphosis in senior women and men with adult-onset hyperkyphosis: results of a randomized controlled trial. J Am Geriatr Soc. (2009) 57:156979. doi: 10.1111/j.1532-5415.2009.02391.x

75. Senthil P, Sudhakar S, Radhakrishnan R, Jeyakumar S. Efficacy of corrective exercise strategy in subjects with hyperkyphosis. J Back Musculoskel Rehabil. (2017) 30:1285-9. doi: 10.3233/BMR-169668

Conflict of Interest: The authors declare that the research was conducted in the absence of any commercial or financial relationships that could be construed as a potential conflict of interest.

The reviewer JN declared a shared affiliation, with no collaboration, with one of the authors, WL, to the handling editor at the time of the review.

Copyright (C) 2020 Koelé, Lems and Willems. This is an open-access article distributed under the terms of the Creative Commons Attribution License (CC BY). The use, distribution or reproduction in other forums is permitted, provided the original author(s) and the copyright owner(s) are credited and that the original publication in this journal is cited, in accordance with accepted academic practice. No use, distribution or reproduction is permitted which does not comply with these terms. 